Journal Club

Editor's Note: These short, critical reviews of recent papers in the Journal, written exclusively by graduate students or postdoctoral fellows, are intended to summarize the important findings of the paper and provide additional insight and commentary. For more information on the format and purpose of the Journal Club, please see http://www.jneurosci.org/misc/ifa_features.shtml.

\title{
Remediating Math Anxiety through Cognitive Training: Potential Roles for Math Ability and Social Context
}

\author{
H. Moriah Sokolowski ${ }^{1}$ and ${ }^{\circledR E l i z a b e t h ~ A . ~ N e c k a ~}{ }^{2}$ \\ ${ }^{1}$ Department of Psychology, University of Western Ontario, London, Ontario N6A 3K7, Canada, and ${ }^{2}$ Department of Psychology, University of Chicago, \\ Chicago, Illinois 60637 \\ Review of Supekar et al.
}

Math anxiety is defined as a negative emotional response to situations involving mathematical problem solving (Ashcraft, 2002). It is a widespread challenge that emerges early during development (Beilock and Willingham, 2014). Childhood math anxiety is associated with long-term effects such as hampered professional achievement in adulthood (Hembree, 1990). Given the well documented adverse effects of this condition, identifying evidence-based approaches to reduce math anxiety is critical (Maloney and Beilock, 2012).

Supekar et al. (2015) recently investigated whether MathWise, an intensive 8 week one-on-one math tutoring program developed by Fuchs et al. (2013), could alleviate math anxiety in elementary school-aged children (7-9 years old). Participants attended three 40-50 min mathematics-tutoring sessions per week. Before and after the intervention, participants underwent functional magnetic resonance imaging (fMRI) and reported math anxiety levels using the Scale for Early Mathematics Anxiety (SEMA; Wu et al., 2012). Participants completed an

Received Nov. 9, 2015; revised Dec. 24, 2015; accepted Dec. 29, 2015.

We thank the Numerical Cognition Lab at the University of Western Ontario for their very helpful comments.

Correspondence should be addressed to $\mathrm{H}$. Moriah Sokolowski, University of Western Ontario, Department of Psychology, Westminster Hall, Room 215, 361 Windermere Road, London, 0N N6A 3K7, Canada. E-mail: hsokolow@uwo.ca.

DOI:10.1523/JNEUROSCI.4039-15.2016

Copyright $\odot 2016$ the authors $\quad 0270-6474 / 16 / 361439-03 \$ 15.00 / 0$ arithmetic problem-solving task (Addition task) and a number-identification task (Control task) during scanning. Researchers categorized participants as high or low math-anxious (HMA and LMA, respectively) using a median split of pre-test SEMA scores. Behavioral and neural responses to the intervention were compared between groups.

Supekar et al. (2015) found that the intervention reduced math anxiety scores and remediated what they called "aberrant neural responses" to math in HMA but not LMA children. The latter was determined by contrasting activation during Addition and Control conditions for each participant and then comparing the average difference in HMA children to that in LMA children. Before tutoring, HMA children showed greater activation than LMA children in the right amygdala, left intraparietal sulcus (IPS), left angular gyrus (AG), right ventral lateral prefrontal cortex (VLPFC), and bilateral superior parietal lobule (SPL). Neural activation in HMA and LMA children was indistinguishable after tutoring.

A potentially important methodological limitation of this study is the fact that participants were not recruited based on their math anxiety levels. Rather, HMA and LMA groups were formed using a median split of a normal sample. Typically, high math anxiety is defined as the uppermost $20 \%$ of the population (Ashcraft and Kirk, 2001). But Supekar and colleagues' (2015) classification method may have included partici- pants with nearly average SEMA scores in the HMA group. Thus, whether their results generalize to more math-anxious individuals is unclear. The unorthodox way that $\mathrm{Su}-$ pekar et al. (2015) defined HMA and LMA groups also makes their repeated use of the term "aberrant" to describe the HMA group is questionable. Indeed, caution is always recommended when attaching evaluative terms like "aberrant" to various subpopulations, especially in studies with designs that fail to clearly distinguish between subpopulations and more typical populations.

Assuming that Supekar et al.'s (2015) findings extend to children with higher math anxiety, however, their paper presents the interesting possibility that an intervention that reduces math anxiety can also alter brain functioning in HMA children. The authors attribute this amelioration of "aberrant" responses to the increased exposure to mathematics provided by the intervention (the authors used the term "exposure" as it is used in behavioral modification therapy, i.e., confronting the subject of your fear). We explore the authors' interpretations of their findings, and suggest additional factors that may also have contributed to this reduction of math anxiety, including individual differences in neural processes supporting math performance and changes in math attitudes.

Supekar et al. (2015) report that during pre-testing, HMA children exhibited greater right amygdala activation than 
LMA children during the Addition task relative to the Control task; this difference was absent during post-testing. They interpret this to mean that HMA children showed greater tutoring-induced changes in amygdala activation than LMA children. However, the authors did not report whether activation during the Addition task was significantly different from activation during the Control task for either group at either time-point, nor did they report a significant change from pretesting to post-testing for either HMA or LMA children. Moreover, Supekar et al.'s (2015) Figure 2 reveals that LMA children may have had a greater amygdala response (reduced activation in the Addition compared with the Control task) than HMA children at pre-testing, and that the HMA group showed similar levels of amygdala activation in Addition and Control tasks both before and after tutoring. Thus, although the authors claim that activation of the right amygdala during addition became more normal in HMA children after tutoring, it appears unlikely that the intervention significantly altered amygdala activity in HMA but not LMA children.

Nevertheless, a whole-brain connectivity analysis revealed an intervention-induced decoupling of bilateral amygdala activation in HMA, relative to LMA children. Supekar et al. (2015) do not report a typical signature of anxiety reduction; namely, a change in coordinated activity between the amygdala and medial prefrontal regions (Kim et al., 2011). This raises the question of whether the neural processes underpinning math anxiety are similar to, or distinct from, other forms of anxiety. Though general anxiety is typically positively associated with math anxiety (Hembree, 1990), Supekar et al. (2015) cannot confirm this association, as the researchers did not measure general anxiety. Still, it is surprising that poorer functional coupling between the amygdala and medial prefrontal regions [typical of other anxieties (Kim et al., 2011)] did not emerge in Supekar et al. (2015). Perhaps the distinctive pattern of amygdala activation in this study is unique to math anxiety. Alternatively, the method used to classify HMA participants by Supekar et al. (2015) might drive this distinction. Coordinated activity between the amygdala and prefrontal areas (as typically observed in other anxieties) may be greater in children with higher levels of math anxiety. Future work should investigate this possibility.

While exposure to mathematics is a likely mechanism through which the intervention remediated math anxiety, we suggest that individual differences in neu- ral processes supporting math performance, and improvements in perceptions of one's math ability, may also have played a role in the effects observed by Supekar et al. (2015). Although it is widely established that math-anxious individuals tend to exhibit poorer math performance than their less anxious peers (Ashcraft and Ridley, 2005), Supekar et al.'s (2015) HMA and LMA groups do not differ in math performance during pre-testing (and they showed comparable math ability improvements after training). The lack of the typically observed negative association between math anxiety and math performance in Supekar et al. (2015) further bolsters the possibility that their HMA group, on average, was not actually mathanxious. Still, Supekar et al. (2015) demonstrated that activation of the IPS, SPL, and $A G$ [regions established as important for mathematical processing (for review, see Dehaene et al., 2003)] was reduced from pre-testing to post-testing in the HMA, but not LMA children. One interpretation of this reduction in brain activation in the HMA children that is consistent with other training studies (Nussbaumer et al., 2015) is that during pre-testing, the HMA children found math problems more challenging than did LMA children. Accordingly, HMA children may have recruited greater neural resources to perform at the same ability level as LMA children. In keeping with this interpretation, the finding of reduced neural activation coupled with enhanced math performance after tutoring suggests that the HMA children may have found arithmetic problems less challenging during post-testing compared with pretesting. Consequently, HMA children may have felt less anxious when completing math problems after the intervention.

It is also possible that the HMA children's perceptions of their math ability may have changed after tutoring, especially when assuming that reductions in neural activation in typical math processing regions at post-testing indicate that children found math problems less challenging. Previous work suggests that perceptions of strong math ability are associated with lower subsequent math anxiety (Ahmed et al., 2012), and these perceptions of math ability explain the standard inverse relationship between math performance and math anxiety (Meece et al., 1990). Furthermore, other important social-cognitive correlates of math anxiety, such as how much individuals value math and consider it an important part of themselves (Hembree, 1990;
Necka et al., 2015), can be reasonably expected to change after intensive one-onone math tutoring. Thus, a potentially positive psychosocial experience of meeting with a tutor may affect HMA children's attitudes toward math and perceptions of math ability. These changes have the potential to influence children's math anxiety and associated underlying neural processes. Generally, children with greater sensitivity to social contexts (Boyce and Ellis, 2005) show more adaptive behavioral responses to interventions (Klein et al., 2006). Thus, if math-anxious individuals are more susceptible to positive or negative environmental associations with mathematics, these children may be more likely to respond to interventions.

Supekar et al.'s (2015) investigation of the impact of an intervention on behavioral and neural processes associated with math anxiety suggests that one-onone intervention programs might promote positive behavioral and neural changes. However, the method by which Supekar et al. (2015) designated individuals as HMA raises concerns about the generalizability of their findings. Thus, further research is necessary for a more thorough understanding of how and why the MathWise intervention successfully ameliorates math anxiety. Though exposure to mathematics is a likely mechanism through which the intervention remediates math anxiety, individual differences in neural processes supporting math performance and changes in math attitudes may also support this remediation. More broadly, Supekar et al. (2015) demonstrated that designs that combine behavioral interventions with concurrent assessments of neural, social, and cognitive processes can be effective for understanding how individual differences are related to intervention efficacy.

\section{References}

Ahmed W, Minnaert A, Kuyper H, van der Werf G (2012) Reciprocal relationships between math self-concept and math anxiety. Learn Indiv Diff 22:385-389. CrossRef

Ashcraft MH (2002) Math anxiety: personal, educational, and cognitive consequences. Direct Psychol Sci 11:181-185. CrossRef

Ashcraft MH, Kirk EP (2001) The relationships among working memory, math anxiety, and performance. J Exp Psychol Gen 130:224-237. CrossRef Medline

Ashcraft MH, Ridley KS (2005) Math anxiety and its cognitive consequences: a tutorial review. In: Handbook of mathematical cognition (Campbell JID, ed.), pp 315-327. New York: Psychology. 
Beilock SL, Willingham DT (2014) Math anxiety: can teachers help students reduce it? Am Educ 38:28-32.

Boyce WT, Ellis BJ (2005) Biological sensitivity to context. I. An evolutionary-developmental theory of the origins and functions of stress reactivity. Dev Psychopathol 17: 271-301. Medline

Dehaene S, Piazza M, Pinel P, Cohen L (2003) Three parietal circuits for number processing. Cogn Neuropsychol 20:487-506. CrossRef Medline

Fuchs LS, Geary DC, Compton DL, Fuchs D, Schatschneider C, Hamlett CL, Deselms J, Seethaler PM, Wilson J, Craddock CF, Bryant JD, Luther K, Changas P (2013) Effects of first-grade number knowledge tutoring with contrasting forms of practice. J Educ Psychol 105:58-77. CrossRef

Hembree R (1990) The nature, effects, and relief of mathematics anxiety. J Res Math Educ 21: 33-46. CrossRef

Kim MJ, Loucks RA, Palmer AL, Brown AC, Solomon KM, Marchante AN, Whalen PJ (2011) The structural and functional connectivity of the amygdala: from normal emotion to pathological anxiety. Behav Brain Res 223: 403-410. CrossRef Medline

Klein Velderman M, Bakermans-Kranenburg MJ, Juffer F, van IJzendoorn MH (2006) Effects of attachment-based interventions on maternal sensitivity and infant attachment: differential susceptibility of highly reactive infants. J Fam Psychol 20:266-274. CrossRef Medline

Maloney EA, Beilock SL (2012) Math anxiety: who has it, why it develops, and how to guard against it. Trends Cogn Sci 16:404-406. CrossRef Medline

Meece JL, Wigfield A, Eccles JS (1990) Predictors of math anxiety and its influence on young adolescents' course enrollment inten- tions and performance in mathematics. J Educ Psychol 82:60-70. CrossRef

Necka EA, Sokolowski HM, Lyons IM (2015) The role of self-math overlap in understanding math anxiety and the relation between math anxiety and performance. Front Psychol 6:1543. CrossRef Medline

Nussbaumer D, Grabner RH, Stern E (2015) Neural efficiency in working memory tasks: the impact of task demand. Intelligence 50: 196-208. CrossRef

Supekar K, Iuculano T, Chen L, Menon V (2015) Remediation of childhood math anxiety and associated neural circuits through cognitive tutoring. J Neurosci 35 : 12574-12583. CrossRef Medline

Wu SS, Barth M, Amin H, Malcarne V, Menon V (2012) Math anxiety in second and third graders and its relation to mathematics achievement. Front Psychol 3:162. CrossRef Medline 